\title{
Corticotrophin Releasing Factor-Induced Synaptic Plasticity in the Amygdala Translates Stress into Emotional Disorders
}

\author{
Donald G. Rainnie, ${ }^{1}$ Richard Bergeron, ${ }^{2}$ Tammy J. Sajdyk, ${ }^{4}$ Madhvi Patil, ${ }^{1}$ Donald R. Gehlert, ${ }^{3}$ and Anantha Shekhar ${ }^{4}$ \\ ${ }^{1}$ Department of Psychiatry and Center for Behavioral Neuroscience, Emory University, Atlanta, Georgia 30322, ${ }^{2}$ Department of Psychiatry, Ottawa Health \\ Research Institute, Ottawa, Ontario, Canada, ${ }^{3}$ Central Nervous System Therapeutic Area, Eli Lilly and Company, Indianapolis, Indiana, and ${ }^{4}$ Department of \\ Psychiatry, Indiana University School of Medicine, Indianapolis, Indiana 46202
}

The amygdala is involved in the associative processes for both appetitive and aversive emotions, and its function is modulated by stress hormones. The neuropeptide corticotrophin releasing factor (CRF) is released during stress and has been linked to many stress-related behavioral, autonomic, and endocrine responses. In the present study, nonanxiety-inducing doses of a potent CRF type 1 and 2 receptor agonist, urocortin $(\mathrm{Ucn})$, was infused locally into the basolateral amygdala (BLA) of rats. After 5 daily injections of Ucn, the animals developed anxiety-like responses in behavioral tests. Intravenous administration of the anxiogenic agent sodium lactate elicited robust increases in blood pressure, respiratory rate, and heart rate. Furthermore, in the absence of any additional Ucn treatment, these behavioral and autonomic responses persisted for $>30 \mathrm{~d}$. Whole-cell patch-clamp recordings from BLA neurons of these hyper-reactive animals revealed a pronounced reduction in both spontaneous and stimulation-evoked IPSPs, leading to a hyperexcitability of the BLA network. This Ucn-induced plasticity appears to be dependent on NMDA receptor and subsequent calcium-calmodulin-dependent protein kinase II (CaMKII) activation, because it is blocked by pretreatment with NMDA receptor antagonists and by coadministration of CaMKII inhibitors. Our results show for the first time a stress peptide-induced behavioral syndrome that can be correlated with cellular mechanisms of neural plasticity, a novel mechanism that may explain the etiological role of stress in several chronic psychiatric and medical disorders.

Key words: urocortin; inhibition; anxiety; basolateral amygdala; in vivo; in vitro

\section{Introduction}

Stress initiates a cascade of hormonal and neuroendocrine responses that enable an organism to adapt to new environmental pressures. However, chronic stress, exaggerated responses to an acute stress, or inadequate termination of the stress response may lead to pathological states, which can affect both the CNS and peripheral end organs. Corticotropin releasing factor (CRF), a 41 amino acid neuropeptide, has been identified as a key neurotransmitter responsible for initiating many of the endocrine, autonomic, and behavioral responses to a variety of stressors (Vale et al., 1981; Smagin et al., 2001). Recent evidence suggests that dysfunction of systems regulating CRF function in the CNS contributes to the etiology of several psychiatric disorders such as anxiety, panic disorder, posttraumatic stress disorder, and depression (Arborelius et al., 1999; Yehuda, 2001).

The amygdala is critical for providing affective salience to sensory information (LeDoux, 2000). Recent functional magnetic resonance imaging studies report that increased amygdala activa-

Received Sept. 2, 2003; revised Feb. 20, 2004; accepted Feb. 21, 2004.

This study was supported by United States Public Health Service Grants R29 MH57016 (D.G.R.), R01 MH65702 (A.S.), and K01 MH61025 (T.J.S.) and the Science and Technology Center Program Center for Behavioral Neuroscience National Science Foundation Agreement IBN-9876754. We thank Stephanie Fitz for technical assistance.

Correspondence should be addressed to Donald G. Rainnie, Department of Psychiatry, Emory University, 1639 Pierce Drive, Suite 4309, Atlanta, GA 30322. E-mail: drainni@emory.edu.

DOI:10.1523/JNEUROSCI.5740-03.2004

Copyright $\odot 2004$ Society for Neuroscience $\quad$ 0270-6474/04/243471-09\$15.00/0 tion is associated with several affective states including not only fear and anxiety (Furmark et al., 1997; Adolphs et al., 1998; Tillfors et al., 2001; Critchley et al., 2002) but also many appetitive responses (Maren, 2003). The amygdala is also a major extrahypothalamic source of CRF-containing neurons and has high expression levels for the two cognate CRF receptors (Palkovits et al., 1983; Van Pett et al., 2000). During periods of stress, CRF is released into the amygdala (Cratty et al., 1995; Merlo et al., 1995), and local CRF receptor activation has been postulated as a substrate for stress-induced alterations in affective behavior (Gray and Bingaman, 1996). The basolateral complex of the amygdala (BLA) is thought to be a critical site of synaptic plasticity that contributes to affective behavior, and we have shown that acute CRF receptor activation in vitro increases the excitability of BLA neurons by modulating expression of a slow afterhyperpolarizing potential (Rainnie et al., 1992a). These data suggest that a stress-induced increase of neuronal activity in the BLA may contribute to states of anxiety often associated with chronic stress.

Removal of tonic inhibition in the BLA by local infusion of GABA antagonists in vivo results in anxiety-like behaviors (Sanders et al., 1995), an effect mimicked by direct stimulation with the CRF agonist urocortin (Ucn) (Sajdyk et al., 1999). Significantly, the cardiovascular and behavioral signs elicited by GABA antagonists can be blocked by preinfusion of NMDA and AMPA receptor antagonists into the BLA (Sajdyk and Shekhar, 1997). 
Also, repeated activation of the BLA results in long-term changes in the sensitivity of the BLA neurons and the development of aversive associations or a chronic anxiety-like state that we termed "priming" (Sanders et al., 1995; Sajdyk et al., 1999; Sajdyk and Gehlert, 2000). These data suggest that an increase in glutamatergic transmission (especially the NMDA receptor-mediated changes) within the BLA may contribute to development and expression of synaptic plasticity and priming-induced chronic anxiety-like responses. The mechanism by which repeated stress can elicit similar long-term behavioral changes is not known. If CRF released during stressful periods can also elicit similar synaptic plasticity within the BLA, it would provide a putative mechanism by which stress could induce similar long-term changes in the amygdala. Here, we report that repeated activation of the CRF receptors in the BLA results in an NMDA receptor-mediated calcium flux and activation of calcium-calmodulin-dependent protein kinase II (CaMKII) cascade, resulting in long-lasting behavioral and cellular changes.

\section{Materials and Methods}

Animals

All experiments were conducted on male Wistar rats (275-300 gm; Harlan Laboratories, Indianapolis, IN), which were individually housed in a temperature-controlled room $\left(72^{\circ} \mathrm{F}\right)$. The housing room was on a computer-controlled $12 \mathrm{hr}$ light/dark cycle (lights on at 6:00 A.M. and off at 6:00 P.M.). Food and water were accessible ad libitum.

\section{Surgical techniques}

Animals were removed from their home cage and placed in a closed Plexiglas box, which was connected to an isoflurane system (MGX Research Machine; Vetamac, Rossville, IN). The animals fitted with arterial and venous catheters were completely anesthetized and then placed on their back with their nose situated in a Plexiglas cone, which allowed for constant infusion of isoflurane. Next, the animals were fitted with femoral arterial and venous catheters as described previously (Sajdyk et al., 1999). After catheterization, the rats were placed into a stereotaxic instrument (Kopf Instruments, Tujunga, CA) with the incisor bar set at $-3.3 \mathrm{~mm}$. Animals in all experimental groups not fitted with catheters were immediately placed in the stereotaxic instrument after administration of anesthesia. Bilateral cannulas were implanted as described previously (Sajdyk and Shekhar, 1997).

\section{Intracranial drug and sodium lactate infusions}

All injections into the BLA were conducted using microinjection cannulas (33 gauge; Plastic Products, Roanoke, VA) that fit into and extended 1 $\mathrm{mm}$ beyond the guide cannulas. Urocortin (Peninsula Laboratories, Belmont, CA) was administered in $1 \%$ bovine serum albumin (BSA) in a total volume of $100 \mathrm{nl} / \mathrm{site}$. A detailed description is provided in previous studies (Sajdyk et al., 1999). A solution of $0.5 \mathrm{M}$ sodium lactate $(10 \mathrm{mg} /$ $\mathrm{kg}$ ) was infused at a rate of $200 \mu \mathrm{l} / \mathrm{min}$. The procedure was also performed as described previously (Sajdyk et al., 1999).

\section{Behavioral measurements}

All behavioral testing was conducted at least $72 \mathrm{hr}$ after surgery. Anxietylike behavior was measured using two methods performed as described previously, a modified social interaction (SI) test (Sajdyk et al., 1999) and the elevated plus-maze (EPM) test (Shekhar, 1993).

\section{Experimental protocol}

Acute administration of Ucn into the BLA. On experimental day 1 , rats were divided into two groups. Group 1 was assigned to Ucn treatment ( $25 \mathrm{fmol}$ ), and group 2 was designated to the vehicle treatment. On day 1 , all animals were injected with vehicle (1\% BSA) into the BLA and then, 30 min later, assessed for baseline levels of anxiety-like behavior in the SI test. On experimental day 3 , groups 1 and 2 were administered the assigned treatment and then, $30 \mathrm{~min}$ later, placed into the SI box. All animals were reinjected with vehicle on day 5 to measure a posttreatment baseline for anxiety-like behavior. After completion of the study, all rats were placed in a cardboard shipping box with bedding and food and water supply and then transported overnight (Baxter, Indianapolis, IN) for the electrophysiological studies.

Chronic administration of Ucn into the BLA in the SI experiments. On experimental day 1 , rats were divided into two groups. Group 1 received Ucn treatment ( $6 \mathrm{fmol}$ ), and group 2 was administered vehicle (1\% BSA). Thirty minutes after treatment on day 1 , all animals were assessed for baseline levels of anxiety-like behavior in the SI test. On experimental days $2-4$, rats in both groups were administered the assigned treatment of vehicle or Ucn and returned to their cages. On experimental day 5, rats in groups 1 and 2 were injected with their assigned treatment and reassessed in the SI test $30 \mathrm{~min}$ later. Immediately after the study, half of the animals in group 1 and all of the animals in group 2 were transported for electrophysiological studies as described previously. The second half of the rats in group 1 were retested each week for an additional 5 weeks in the SI test. No additional injections of Ucn were made during this time. During week 5, the animals were given an intraperitoneal injection of alprazolam $(1 \mathrm{mg} / \mathrm{kg})$ and, $30 \mathrm{~min}$ later, placed in the SI test for behavioral assessment.

Chronic administration of Ucn into the BLA in EPM experiments. On experimental day 1 , all rats received $U \mathrm{cn}(6 \mathrm{fmol})$ and were placed on the EPM 30 min later. On experimental days 2-5, rats were injected with $U \mathrm{cn}$ and placed back in their home cages. No additional injections of Ucn were made, and the rats in this group were reassessed on the EPM on experimental day 14. The rats were not reassessed in the EPM test, because there is evidence that there is significant trial-to-trial learning if this test is repeated too many times (File et al., 1990).

Chronic administration of Ucn into the BLA in the lactate infusion experiments. On experimental day 1 , all rats received an intravenous injection of sodium lactate, the heart rate, blood pressure, and respiration were recorded throughout, and then they were immediately placed in the SI test. On experimental days 2-4, rats were administered Ucn $(6 \mathrm{fmol} /$ side). On day 5 , all rats again received an intravenous infusion of sodium lactate, their heart rate, blood pressure, and respiration were recorded, and they were tested in the SI test.

Coadministration of Ucn and the NMDA antagonist AP-5 into the BLA. On experimental day 1 , animals were separated into two groups. Group 1 received the active form of the NMDA antagonist AP-5 (racemic DLAP-5, 100 pmol) in solution with $\mathrm{Ucn}(6 \mathrm{fmol})$, and group 2 received the inactive isomer L-AP-5 in solution with $\mathrm{Ucn}(6 \mathrm{fmol})$. Thirty minutes after the Ucn injection, all animals were behaviorally assessed in the SI test. This same protocol was repeated on days $2-4$, except no behavioral testing was conducted. On day 5 , animals in both groups were administered the assigned drug injections and then reassessed in the SI test 30 min later.

Coadministration of Ucn and the CaMKII antagonist 1-[N, O,-bis-(5isoquinolinesulfonyl)-N-methyl-L-tyrosl]-4-phenylpiperazine into the BLA. On experimental day 1, animals were separated into two groups. Group 1 received 1 - $[N, O$,-bis-(5-isoquinolinesulfonyl)- $N$-methyl-L-tyrosl $]-4$ phenylpiperazine (KN-62) (1 fmol) $30 \mathrm{~min}$ before $\mathrm{Ucn}$ (6 fmol), and group 2 received vehicle (1\% BSA) $30 \mathrm{~min}$ before $\mathrm{Ucn}(6 \mathrm{fmol})$. Thirty minutes after the second injection, all animals were behaviorally assessed in the SI test. This same protocol was repeated on days $2-4$, except no behavioral testing was conducted. On day 5 , animals in both groups were administered $\mathrm{KN}-62$ ( $1 \mathrm{fmol}) 30 \mathrm{~min}$ before $\mathrm{Ucn}(6 \mathrm{fmol})$ and then reassessed in the SI test $30 \mathrm{~min}$ later.

\section{Electrophysiological studies}

Selection of animals. All animals were color coded such that the behavioral status of the animals used in these experiments was unknown to the experimenter at the time of recording. Animals that received a single daily bilateral injection of vehicle for $5 \mathrm{~d}$ are termed "sham-primed" animals, and those receiving daily injections of urocortin for $5 \mathrm{~d}$ are termed "Ucn-primed" animals.

Preparation of acute slices from the BLA. Neuronal responses reported in this study were obtained only from neurons located in the basolateral subdivision of the basolateral complex (BLA). Slices (500 $\mu \mathrm{m}$ thick) containing the basolateral complex were obtained from 30- to 60-d-old male Wistar rats, anesthetized with isoflurane before decapitation, and 
prepared using procedures as described previously (Rainnie, 1999). Slices were maintained fully submerged in a tissue chamber and continuously perfused with artificial CSF (ACSF) of the following composition (in mM): $124 \mathrm{NaCl}, 3.75 \mathrm{KCl}, 1.25 \mathrm{KH}_{2} \mathrm{PO}_{4}, 1.3 \mathrm{MgCl}_{2}, 3.5 \mathrm{CaCl}_{2}, 26$ $\mathrm{NaHCO}_{3}$, and 10 glucose. The ACSF was heated to $32 \pm 2{ }^{\circ} \mathrm{C}$ and gassed with a $95 / 5 \%$ oxygen/carbon dioxide mixture. Whole-cell patch-clamp recordings were obtained using standard recording techniques. Briefly, borosilicate glass patch electrodes (resistance, $4-6 \mathrm{M} \Omega$ ) were pulled on a Flaming-Brown micropipette puller (model P-87; Sutter Instruments, Novato, CA) and filled with: $130 \mathrm{~mm}$ K-gluconate, $10 \mathrm{~mm}$ phosphocreatinine, $3 \mathrm{~mm} \mathrm{KCl}, 10 \mathrm{~mm}$ HEPES, $3 \mathrm{~mm} \mathrm{MgCl}_{2}$, 2 mм MgATP, $0.2 \mathrm{~mm}$ $\mathrm{NaGTP}$, and $0.25 \%$ biocytin. Patch solution was buffered to $\mathrm{pH} 7.2$ and had an osmolarity of $280 \mathrm{mOsm}$. Recordings were made with an Axopatch-1D amplifier (Axon Instruments, Burlingame, CA) using pClamp 8.0 software and a Digidata 1320 A-D interface (Axon Instruments). For stimulation of afferent fibers, a concentric bipolar stimulating electrode (MCE-100; Kopf Instruments, Tujunga, CA) was placed either on the fibers of the stria terminalis (ST) or in the lateral nucleus of the amygdala (LA).

Patch-clamp recordings. Only those BLA neurons having a stable resting membrane potential (RMP) of less than $-55 \mathrm{mV}$ and an action potential that overshot $+5 \mathrm{mV}$ were considered acceptable for additional analysis. All data were sampled at a frequency determined by the speed of the response to be measured. Data were filtered at $5 \mathrm{kHz}$ in current clamp and $2 \mathrm{kHz}$ in voltage clamp. For acquisition of evoked and spontaneous postsynaptic potentials (PSPs) and postsynaptic currents (PSCs), data were sampled at $20 \mathrm{kHz}$.

Analysis of synaptic events. Spontaneous and stimulus-evoked synaptic potentials were recorded at a standardized holding potential of $-60 \mathrm{mV}$. For stimulation studies, the stimulation intensity was set at a point midway between a $50 \%$ failure rate and threshold for action potential generation. Single stimuli were applied at $0.2 \mathrm{~Hz}$ and repeated five times. Evoked potentials were then averaged, and the peak EPSP and IPSP amplitude measured relative to the holding potential $(-60 \mathrm{mV})$. Spontaneous EPSPs and IPSPs were captured continuously for $1 \mathrm{~min}$ at a sampling frequency of $20 \mathrm{kHz}$. Spontaneous potentials were detected and analyzed using the Mini Analysis Program (Synaptosoft, Decatur, GA). Detection criteria for spontaneous EPSPs included a $0.5 \mathrm{mV}$ event threshold, a rise time of $<7 \mathrm{msec}$, and a decay curve that approximated to an exponential decay. All detected events were then visually inspected to ensure that they met criteria. Individual events were aligned by the rise time and averaged to obtain the mean peak amplitude and duration. Detection criteria for spontaneous IPSPs included a $1 \mathrm{mV}$ event threshold and a rise time of $<40 \mathrm{msec}$.

Drug application. Drugs were applied directly to the ACSF using a continuous gravity-fed bath application. Bicuculline methiodide (Bic; $20-50 \mu \mathrm{M}$ ) was applied to examine residual $\mathrm{GABA}_{\mathrm{A}}$ receptor activity and was purchased from Research Biochemicals International (Natick, MA).

Statistical analysis. For in vivo experiments, a repeated measure with ANOVA using a Newman-Keul's post hoc analysis was used for animals in week $5 \mathrm{Ucn}$ and AP-5 studies, whereas a paired $t$ test was used to analyze the data from all other experiments. The $\alpha$ level was set at 0.05 . Only those animals with a correct placement of both cannulas were used in the statistical analysis. For in vitro experiments, means, SD, and SEM were calculated for each treatment, and two-tailed paired and unpaired Student's $t$ tests or Mann-Whitney $U$ tests were performed as necessary. Data are expressed as mean \pm SEM, and significance was accepted if $p<$ 0.05 .

\section{Results}

\section{In vivo experiments}

Chronic administration of Ucn into the BLA

Animals administered a subthreshold dose $(6 \mathrm{fmol}$; a dose that does not acutely induce an anxiety-like response) (Sajdyk et al., 1999) of Ucn once daily for $5 \mathrm{~d}$ show a significant reduction in the amount of time spent in the open arm of an elevated plus-maze as well as the number of entries made into the open arm on day 5 compared with day 1 (Fig. $1 A, B$ ). In addition, Ucn-primed ani-

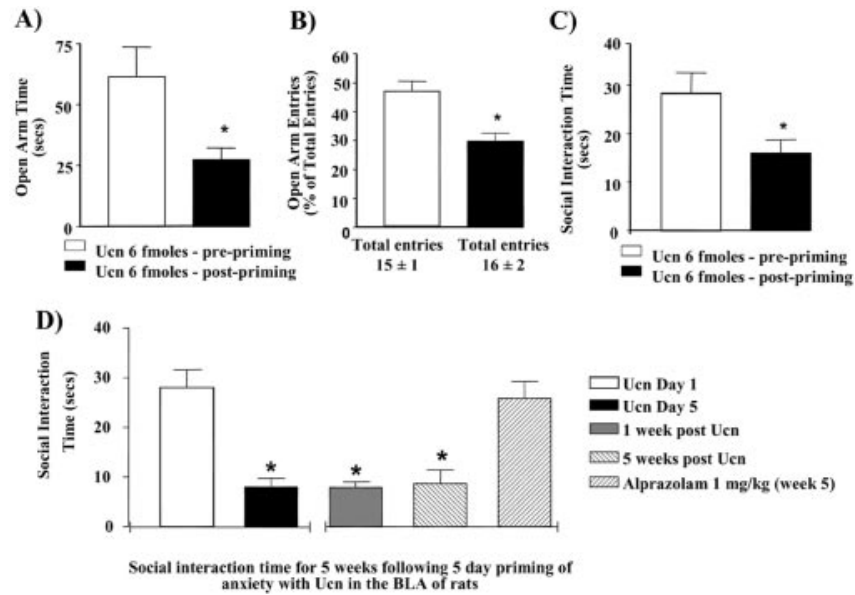

Figure 1. Repeated activation of the CRF receptors in the BLA results in long-lasting increases in anxiety responses. Anxiety responses as measured by the elevated plus-maze test before and after five daily injections of $U$ cn into the BLA are shown. $A, B$, The effects of $U$ en on the elevated plus-maze test measured as a percentage of open arm time $(t=26.46 ; p=0.0014$; $n=3)(A)$ and a percentage of open arm entries $(t=4.663 ; p=0.04 ; n=3)(B)$ show increases in anxiety by day 5 (Ucn, $6 \mathrm{fmol}$, after priming) compared with day 1 (Ucn, $6 \mathrm{fmol}$, before priming). C, D, Administration of Ucn daily for $5 \mathrm{~d}$ also elicits a significant decrease in social interaction time by day 5 , compared with day 1 ( $(C)$, and continues to remain decreased for an additional 5 weeks or until the animals are treated with the anxiolytic alprazolam $(D)$ $\left(F_{(3,15)}=17.56 ; p=0.00001 ; n=4\right)$. Difference from day $1\left(^{*}\right)$ and from alprazolam (\#) by ANOVA with student Newman-Keul's test is shown; $p<0.001$.
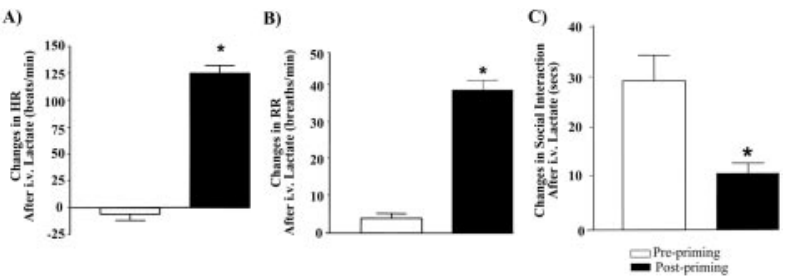

Figure 2. Administration of Ucn for 3 d results in increased autonomic and behavioral reactivity to peripheral anxiogenic stimuli such as sodium lactate infusions. Another group of animals primed with Ucn for 3 d demonstrates that they not only show increased baseline anxiety responses but also become reactive to sodium lactate infusions (15 min administration; 10 $\mathrm{ml} / \mathrm{kg} ; 0.5 \mathrm{~m}$ solution). $A-C$, The group differences in heart rate $(A)$, respiratory rate $(B)$, and responses $(C)$ in the social interaction test of anxiety before and after priming clearly demonstrate an increased physiological and behavioral reactivity after priming, suggesting greater stress vulnerability. Asterisk, Significantly different from prepriming by paired $t$ test; ${ }^{*} p<$ $0.0001(n=6)$.

mals show a significant decrease in social interaction time by day 5 and continue to exhibit this enhanced anxiety-like behavior in the absence of any further Ucn challenge for an additional 5 weeks (Fig. 1C,D). Significantly, the reduced SI (anxiety-like) behavior in Ucn-primed animals can be prevented if the animals are administered the anxiolytic agent alprazolam $(1 \mathrm{mg} / \mathrm{kg})$ (Fig. $1 D)$. However, the effect of alprazolam in Ucn-primed rats was decreased in magnitude when examined in the SI test compared with vehicle-treated rats (data not shown), suggesting that the Ucn-primed animals are still responsive to anxiolytic treatments, but the response was attenuated. In agreement with previous studies (Sajdyk et al., 1999), animals challenged after priming with intravenous sodium lactate, a known inducer of anxiety responses in humans with panic disorder (Maddock, 2001), showed significant changes in heart rate (Fig. 2A), respiration rate (Fig. $2 B$ ), and anxiety-like behavior (Fig. 2C) when compared with their prepriming sodium lactate response. 
Chronic anxiety-like behavior induced by $C R F$-mediated plasticity in the BLA is NMDA receptor dependent

During Ucn priming, daily coadministration of the active form of the NMDA receptor antagonist, DL-AP-5 (100 pmol), into the BLA blocked development of the anxiogenic response to $\mathrm{Ucn}$, suggesting that local NMDA receptor activation is necessary for the development of the priming response (Fig. $3 A$ ). In contrast, coadministration of the inactive form L-AP-5 did not block the anxiogenic response (data not shown). Similarly, once the anxiety-like behavior was established, coadministration of DL-AP-5 (100 pmol) on day 5 failed to block the behavioral response (Fig. 3B).

\section{CRF-mediated plasticity in the BLA requires CaMKII activation} Administration of the specific CaMKII inhibitor KN-62 (1 fmol) $30 \mathrm{~min}$ before each of the five daily Ucn injections completely abolished the anxiogenic response to Ucn priming (Fig. $3 C$ ). However, once $\mathrm{Ucn}$ priming is established with the $5 \mathrm{~d}$ priming schedule, injection of KN-62 on day 5, 30 min before a subthreshold Ucn challenge, did not attenuate the Ucn-induced anxiogenic response (Fig. 3D).

Acute administration of Ucn into the BLA

Animals administered acute anxiogenic doses of Ucn ( $25 \mathrm{fmol})$ showed a significant reduction in SI time compared with pretreatment and post-treatment baselines with no overall change in either of the baseline values $\left(F_{(2,4)}=5.760 ; p=0.0282 ; n=5\right.$; data not shown).

\section{In vitro experiments}

The observation that $5 \mathrm{~d}$ of Ucn priming of the BLA results in an elevation of baseline anxiety that is maintained for at least 5 weeks in the absence of any additional Ucn challenge suggests that repeated Ucn application could cause a restructuring of the intrinsic neural network of the BLA. Consequently, we examined the possible cellular substrates mediating the change in behavior associated with the Ucn-priming phenomenon. Here, we used whole-cell patch-clamp recording from an in vitro brain slice preparation to compare the membrane properties and synaptic potentials observed in BLA neurons from Ucn-primed and sham-primed control animals.

We and others have documented the electrophysiological properties and synaptic input of BLA neurons (Rainnie et al., 1993; Mahanty and Sah, 1999). Of the 169 neurons recorded, 152 neurons were presumed projection neurons, and 17 were presumed interneurons. Here, we report only those recordings obtained from presumed projection neurons, unless otherwise stated.

Urocortin priming does not affect the passive membrane properties of BLA projection neurons

The passive membrane properties obtained from 69 projection neurons in 17 control animals and 51 projection neurons from 12 Ucn-primed animals are summarized in Table 1. Five day Ucn priming had no significant effect on either the RMP or the time constant for membrane charging $(\tau)$. Although the membrane input resistance of control projection neurons showed a trend toward higher values than those from Ucn-primed animals, this was not statistically significant $(89.0 \pm 8.2$ vs $69.8 \pm 5.4 \mathrm{M} \Omega$,
Table 1. Intrinsic membrane properties of BLA projection neurons and BLA interneurons

\begin{tabular}{|c|c|c|c|c|}
\hline & \multirow[b]{2}{*}{ (n) } & \multicolumn{3}{|c|}{ Passive membrane properties } \\
\hline & & $\mathrm{RMP}(\mathrm{mV})$ & $\operatorname{Rm}(M \Omega)$ & $\tau(\mathrm{mS})$ \\
\hline \multicolumn{5}{|l|}{ Projection neurons ${ }^{a}$} \\
\hline Chronic vehicle & 69 & $-60.0 \pm 0.9$ & $89.0 \pm 8.2$ & $19.6 \pm 1.0$ \\
\hline Acute Ucn & 11 & $-61.7 \pm 0.8$ & $71.5 \pm 8.8$ & $21.4 \pm 3.1$ \\
\hline Chronic Uen & 51 & $-60.2 \pm 0.2$ & $69.7 \pm 5.3$ & $21.1 \pm 1.5$ \\
\hline \multicolumn{5}{|l|}{ Interneurons $^{b}$} \\
\hline Control vehicle & 8 & $-61.7 \pm 1.9$ & $148.0 \pm 31.0$ & $18.6 \pm 2.8$ \\
\hline Chronic Uen & 8 & $-60.5 \pm 0.8$ & $190.5 \pm 30.1$ & $16.5 \pm 1.1$ \\
\hline
\end{tabular}

Rm, Resting membrane input resistance.

${ }^{a}$ No significant difference was observed in the intrinsic membrane properties of BLA projection neurons.

${ }^{b}$ No significant difference was observed in the intrinsic membrane properties of BLA interneurons.

respectively; $p=0.7)$. Moreover, $\mathrm{Ucn}$ priming caused no change in the number and frequency of action potentials generated in BLA projection neurons in response to depolarizing current injection (data not shown). Similarly, no significant difference was observed in the passive membrane properties of BLA interneurons (Table 1).

\section{Urocortin priming reduces the expression of spontaneous} inhibitory synaptic potentials in BLA projection neurons In $80 \%$ of BLA neurons, the most prominent spontaneous synaptic events recorded close to the RMP $(-60 \mathrm{mV})$ are rhythmic $(\sim 1 \mathrm{~Hz})$, long duration $(\sim 250-500 \mathrm{mS})$, and $\mathrm{GABA}_{\mathrm{A}}$ receptormediated IPSPs (Rainnie et al., 1991b; Smith and Dudek, 1996) interspersed on a background of higher frequency $(\sim 14 \mathrm{~Hz})$ glutamatergic EPSPs (Rainnie et al., 1991a). In agreement with these previous studies, the majority of neurons (72\%) recorded from the sham-primed group showed a pattern of spontaneous IPSPs and EPSPs similar to that reported previously (Fig. $4 A$, top trace). Hence, repeated injection of vehicle alone does not appear to disrupt synaptic transmission in the BLA. In contrast, the majority of neurons from Ucn-primed animals (64\%) displayed rhythmic long-duration EPSPs in addition to the high-frequency short-duration EPSPs normally observed in projection neurons and no apparent IPSPs (Fig. $4 A$, bottom trace).

The normal reversal potential for spontaneous $\mathrm{GABA}_{\mathrm{A}}$ receptor-mediated IPSPs $\left(\mathrm{E}_{\mathrm{IPSP}}\right)$ is approximately $-70 \mathrm{mV}$. At more negative membrane potentials, the IPSP inverts and has the appearance of an EPSP (Rainnie et al., 1991b). Consequently, it was possible that the Ucn-priming schedule caused a depolarizing shift in the reversal potential for the $\mathrm{GABA}_{\mathrm{A}}$ receptormediated IPSPs. Therefore, we examined neurons from Ucnprimed animals for a depolarizing shift in the IPSP reversal potential. However, manual depolarization of the membrane potential to $-45 \mathrm{mV}$ with $\mathrm{DC}$ current injection failed to unmask any inhibitory component to the rhythmic synaptic potentials 


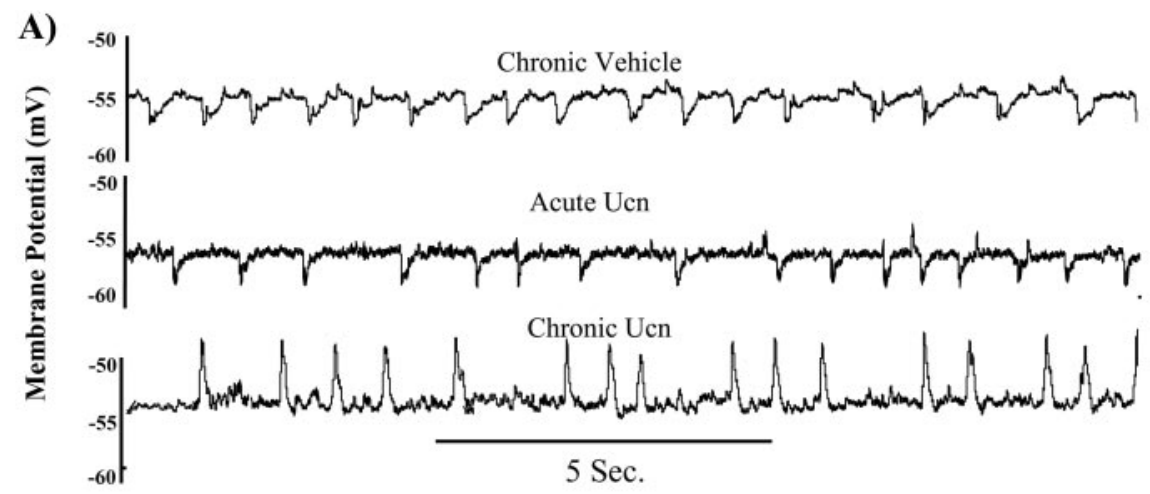

B)

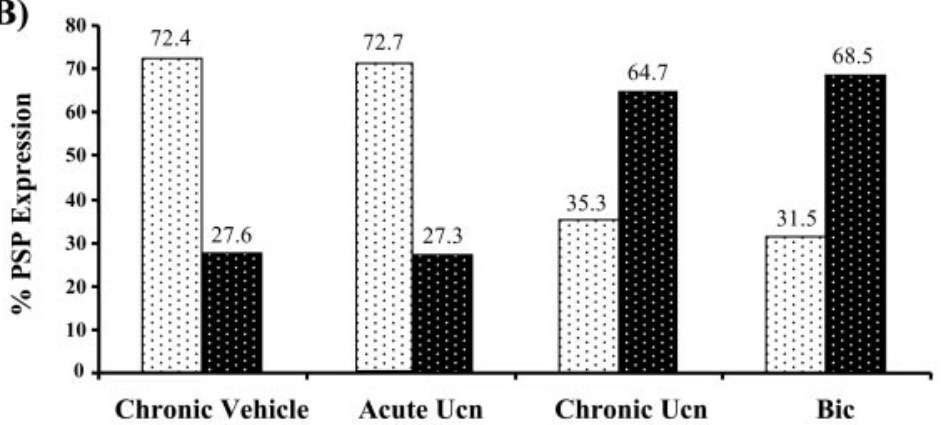

Spont EPSP/IPSP

C)

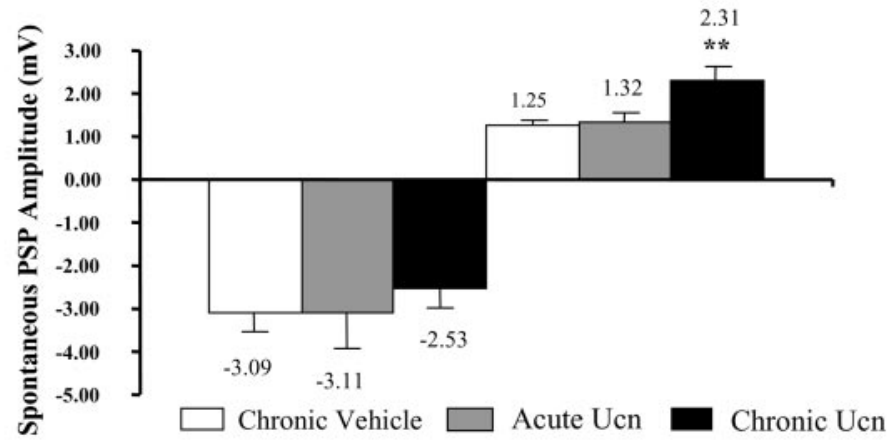

Figure 4. Chronic Ucn priming reduces the expression of spontaneous inhibitory synaptic potentials. A, Typical spontaneous PSPs observed in BLA projection neurons recorded from sham-primed control animals (top trace), acute Ucn-treated animals (middle trace), and Ucn-primed animals (bottom trace). Note the absence of spontaneous inhibitory synaptic potentials (downward deflections) in the trace from the chronic Ucn-primed animals. B, Bar histograms showing the percentage of cells that expressed both spontaneous EPSPs and IPSPs versus the percentage of cells that expressed only spontaneous EPSPs in each test group (chronic vehicle, $n=66$; acute Ucn, $n=11$; chronic Ucn, $n=51$; Bic, $n=21$ ). C, A significant increase in the amplitude of the spontaneous EPSPs was observed in the group of rats chronically treated with Ucn.

(data not shown). Moreover, the $\mathrm{E}_{\mathrm{IPSP}}$ in $35 \%$ of BLA neurons from Ucn-primed animals that did express spontaneous IPSPs was not different from that reported previously $(-69 \pm 2.6 \mathrm{mV}$; $n=6$ ). These data suggest that in the majority of animals, $U c n$ priming results in a decrement in the expression of GABAergic inhibition within the BLA, similar to that observed after kindling of the amygdala (Rainnie et al., 1992b). In agreement with this hypothesis, direct in vivo manipulation of BLA GABA $\mathrm{A}_{\mathrm{A}}$ receptors using subthreshold doses of the $\mathrm{GABA}_{\mathrm{A}}$ receptor antagonist, bicuculline methiodide, induces an anxiogenic response (Sanders et al., 1995) that is indistinguishable from that observed after Ucn priming. Here, we show that the pattern of spontaneous synaptic potentials observed in BLA projection neurons recorded from Ucn-primed animals is identical to the pattern observed in BLA neurons from bicuculline-treated animals (Fig. 4B). In ad- dition, in those neurons expressing spontaneous IPSPs, no significant difference was observed in the peak amplitude measured at the holding potential of $-60 \mathrm{mV}$ (Fig. 4C, left). In contrast, a significant increase in the amplitude of spontaneous EPSPs was observed in the chronic Ucntreated animal (Fig. $4 C$, right). These data would suggest that a common deficit in $\mathrm{GABA}_{\mathrm{A}}$ receptor-mediated neurotransmission may contribute to the etiology of the anxiogenic behavior observed in these two paradigms.

We next examined whether the reduced expression of spontaneous IPSPs in projection neurons from Ucn-primed animals could result from a disruption of $\mathrm{GABA}_{\mathrm{A}}$ receptor-effector coupling. To address this issue, we examined the direct postsynaptic response of BLA neurons to transient $(100 \mathrm{mS})$ pressure ejection of the $\mathrm{GABA}_{\mathrm{A}}$ receptor agonist, muscimol (100 $\mu \mathrm{M})$, in the presence of tetrodotoxin (1 $\mu \mathrm{M})$. No significant difference was found in the response of BLA neurons from control or Ucn-primed animals to transient muscimol application (Fig. 5) $(n=6$ for each group). These data suggest that postsynaptic $\mathrm{GABA}_{\mathrm{A}}$ receptor function is unaltered by the Ucn-priming schedule.

Ucn priming attenuates stimulus-evoked inhibitory responses in BLA

projection neurons

The loss of spontaneous inhibitory synaptic potentials observed in Ucn-primed animals could also be explained by a decrement in the excitatory drive onto local circuit interneurons. Hence, we next examined the response of BLA neurons to electrical stimulation of the ST and LA. In agreement with our previous studies (Rainnie et al., 1991b), stimulation of either afferent pathway in sham-primed control animals evoked PSPs that included a fast IPSP (fIPSP) and slow IPSP (sIPSP) GABAergic component in $89 \%$ of all neurons tested (Fig. 6) $(n=50)$. In contrast, only $42 \%$ of neurons from Ucn-primed animals showed any GABAergic inhibitory component of the evoked PSP (Fig. 6) $(n=35)$. Significantly, in this subset of BLA neurons, afferent stimulation evoked only a slow $\mathrm{GABA}_{\mathrm{B}}$ receptor-mediated IPSP and no $\mathrm{GABA}_{\mathrm{A}}$ receptor-mediated fast IPSP (Fig. 6). Moreover, the amplitude and duration of the evoked EPSP was significantly greater in neurons recorded from Ucn-primed animals $(6.8 \pm 0.8 \mathrm{mV})$ compared with controls ( $4.3 \pm 0.7 \mathrm{mV} ; p=0.008 ; n=15)$, as might be expected if the shunting effect of the fast $\mathrm{GABA}_{\mathrm{A}}$ receptor-mediated IPSP has been removed. However, spontaneous epileptiform burst-firing activity, a characteristic of BLA neurons from kindled animals, was not observed in any of the projection neurons recorded from Ucn-primed animals. Indeed, epileptiform burst-firing activity could be induced in Ucn-primed neurons after application of the 


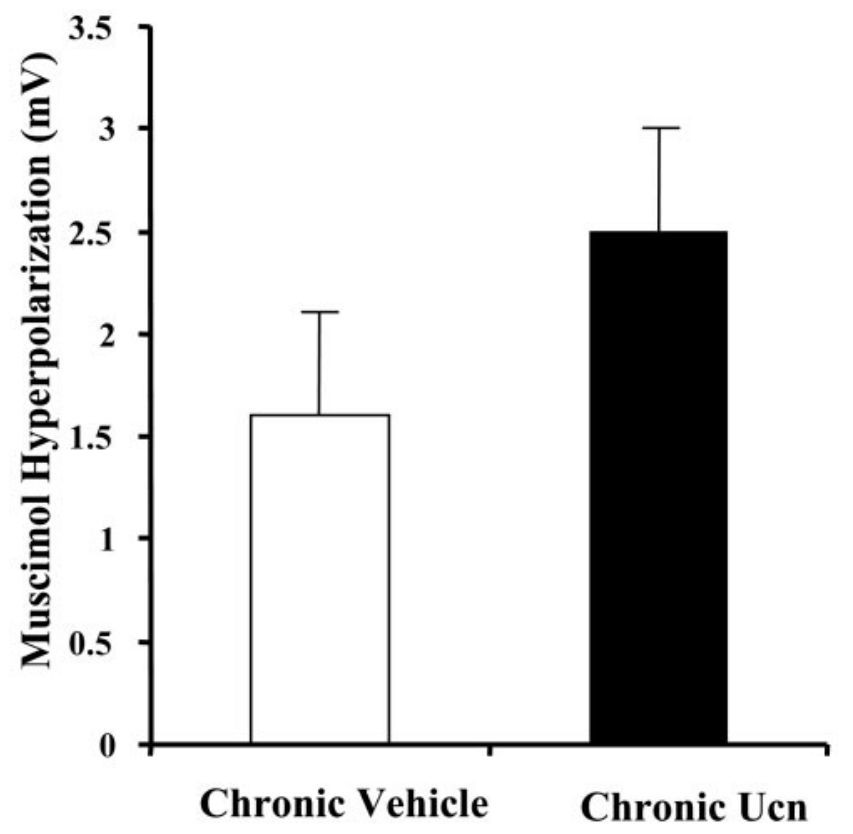

Figure 5. Chronic Ucn treatment does not significantly alter intrinsic membrane properties of the BLA neurons. No significant difference was observed in the direct, postsynaptic, hyperpolarizing response to muscimol applied by pressure ejection after Ucn priming.
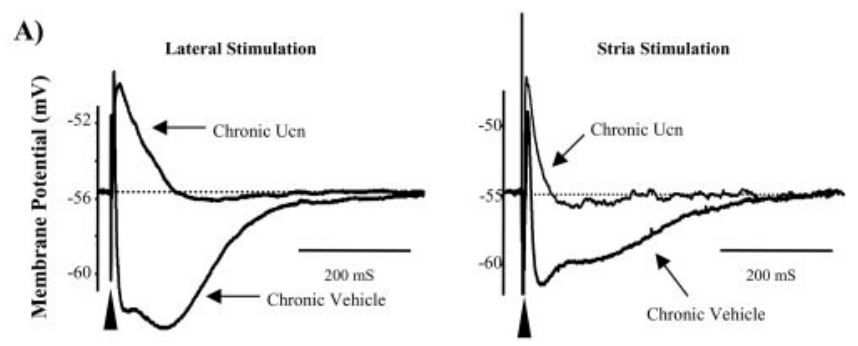

B)

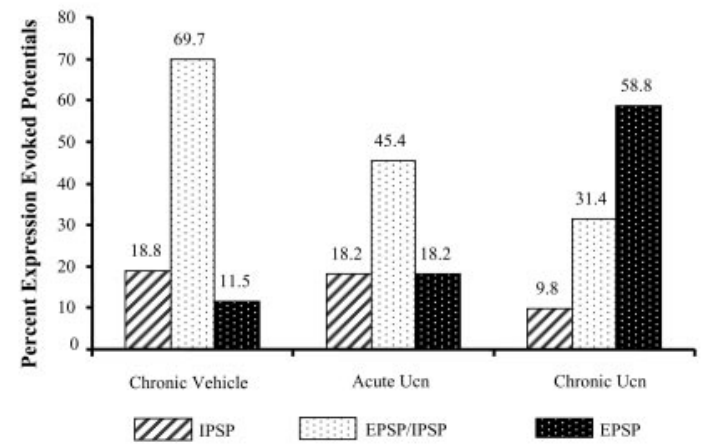

Figure 6. Chronic Ucn priming attenuates stimulus-evoked inhibition in BLA projection neurons. A, Typical stimulation-evoked postsynaptic response profiles recorded from BLA neurons after stimulation of the lateral nucleus of the amygdala (left traces) or stria terminalis (right traces). Ucn priming almost completely abolishes the evoked IPSP in both pathways resulting in a concomitant increase in the duration of the evoked EPSP. B, Group data showing the response profile of all neurons sampled from each test group (chronic vehicle, acute Ucn, and chronic Ucn treatment). Note the shift in response from predominantly inhibitory responses to predominantly excitatory responses after Ucn priming.

$\mathrm{GABA}_{\mathrm{A}}$ receptor antagonist bicuculline methiodide (30 $\mu \mathrm{M}$; data not shown). These data suggest that the anxiogenic behavior induced by $U \mathrm{cn}$ priming results from a subtle reduction of inhibitory control in the BLA neural network, together with a concomitant increase in excitatory drive, and not as an indirect consequence of temporal lobe seizures.
Table 2. Summary of the difference in the amplitude of EPSPs, fIPSPs, and sIPSPs after electrical stimulation of the stria terminalis or lateral nucleus of the amygdala

\begin{tabular}{lllll}
\hline \multirow{2}{*}{ Treatment } & Stimulation & Amplitude & & \\
\cline { 3 - 5 } & EPSP $(\mathrm{mV})$ & fIPSP $(\mathrm{mV})$ & SIPSP $(\mathrm{mV})$ \\
\hline \multirow{2}{*}{ Chronic vehicle } & LA & $4.3 \pm 0.7$ & $-2.6 \pm 0.6$ & $-2.6 \pm 0.3$ \\
& ST & $3.3 \pm 0.6$ & $-2.9 \pm 0.5$ & $-1.5 \pm 0.6$ \\
Acute Ucn & LA & $3.9 \pm 0.9$ & $-2.3 \pm 0.6$ & $-2.5 \pm 0.3$ \\
& ST & NA & NA & NA \\
Chronic Ucn & LA & $6.8 \pm 0.7^{* *}$ & $0.0(n=15)$ & $-2.4 \pm 0.4$ \\
\hline NA, Not applicable; ${ }^{* *}$, , & STatistical significance, $p<0.05$. & &
\end{tabular}

Changes in the electrophysiological properties of BLA neurons are not attributable to an acute anxiety response

It was possible that the long-lasting synaptic changes observed in Ucn-primed animals did not correlate with the gradual process of priming but rather occurred as a result of a single anxiogenic response to $\mathrm{Ucn}$. If this were true, we would expect to see a similar change in network excitability after a single bilateral infusion of an anxiogenic dose of Ucn ( $25 \mathrm{fmol})$. In all animals tested, this dose of $U \mathrm{cn}$ produced a marked reduction in social interaction time $(n=$ 12). However, there was no significant difference between control vehicle-injected animals and Ucn-injected animals for any of the resting membrane properties or spontaneous synaptic potentials examined above (Figs. 4, 6B, acute Ucn). Similarly, stimulation of either the ST or LA pathways evoked a $\mathrm{GABA}_{\mathrm{A}}$ receptor-mediated IPSP in $83 \%$ of projection neurons from acute Ucn-infused animals (Fig. 6B, Table 2). These data would suggest that a single anxietyinducing dose of $U \mathrm{cn}$ does not result in a long-lasting alteration in network excitability in the BLA.

\section{Discussion}

Our results demonstrate that repeat administration of Ucn into the BLA, in a dose that acutely does not alter behavioral responses in the SI and EPM tests, induced long-lasting anxiety-like responses that persist for weeks. This long-term behavioral sensitization was dependent on activation of an NMDA receptormediated CaMKII-dependent second messenger cascade. Moreover, at the cellular level, the prolonged alteration of affective state was associated with a concomitant increase of BLA network excitability resulting from a specific loss of $\mathrm{GABA}_{\mathrm{A}}$ receptor-mediated inhibition. This novel mechanism could help explain how CRF-induced synaptic plasticity in the BLA contributes to the pathogenesis of several stress-related disorders such as anxiety, depression, and cardiovascular diseases.

In several species, intracerebroventricular (ICV) injections of CRF induce a behavioral state akin to arousal and anxiety (Sutton et al., 1982; Callahan et al., 1991) as measured in the conflict test (Heinrichs et al., 1992), social interaction (Dunn and File, 1987), acoustic startle (Swerdlow et al., 1986), and elevated plus maze (Britton et al., 1986). Similarly, transgenic mice that overproduce CRF show increased anxiety-like behaviors, and this phenomenon is reversed by central administration of the CRF antagonist $\alpha$-helical CRF 9-41 (Stenzel-Poore et al., 1996). Lee et al. (1994) subsequently demonstrated that local infusion of a nonspecific CRF receptor antagonist into the amygdala was sufficient to attenuate ICV CRF-enhanced acoustic startle. Recent functional studies of $\mathrm{CRF}_{1}$ and $\mathrm{CRF}_{2}$ receptors suggest that $\mathrm{CRF}_{1}$ receptor activation mediates the anxiogenic-like properties of CRF, whereas $\mathrm{CRF}_{2}$ receptor activation may be anxiolytic (Heinrichs et al., 1997; Bale et al., 2000; Reul and Holsboer, 2002). Urocortinn has a $45 \%$ sequence homology with CRF (Vaughan et al., 1995) 
and, although CRF is equipotent at both $\mathrm{CRF}_{1}$ and $\mathrm{CRF}_{2}$ receptors, $\mathrm{Ucn}$ has a similar affinity for $\mathrm{CRF}_{1}$ receptors as CRF but a higher affinity for $\mathrm{CRF}_{2}$ receptors. Importantly, $\mathrm{CRF}_{1}$ and $\mathrm{CRF}_{2}$ receptors differentially distributed in the $\mathrm{CNS}$, and only $\mathrm{CRF}_{1}$ receptors are expressed in the rodent BLA (Van Pett et al., 2000). These data suggest that the enhancement of aversive associations or anxiogenic-like responses after $U \mathrm{cn}$ priming in the BLA probably results from $\mathrm{CRF}_{1}$ receptor activation. In agreement, mice lacking a functional $\mathrm{CRF}_{1}$ receptor show decreased stressinduced anxiety-like behavior (G. W. Smith et al., 1998; Timpl et al., 1998).

Our data also suggest that the behavioral response induced by Ucn priming in the BLA results from a specific reduction of fast $\mathrm{GABA}_{\mathrm{A}}$ receptor-mediated inhibition and a concomitant increase in glutamatergic drive onto BLA projection neurons. In agreement, a recent study using immunohistochemical markers of cell activity has reported that ICV CRF administration induces bilateral activation of the BLA (Dube et al., 2000). Basal activity of BLA projection neurons is maintained by a fine balance between the level of glutamatergic excitatory afferent input and local circuit inhibitory input from GABAergic nonpyramidal cells. Previous studies have shown that the excitatory drive onto BLA neurons primarily results from activation of AMPA receptors, but that NMDA receptors can also be activated at the resting membrane potential of these neurons (Rainnie et al., 1991a; Gean and Chang, 1992; Li et al., 1995). However, the NMDA receptormediated excitation temporally overlaps with a fast $\mathrm{GABA}_{\mathrm{A}}$ receptor-mediated inhibitory input, which rapidly terminates the excitatory response.

If the GABAergic inhibition is reduced in the BLA, then the NMDA receptor-mediated excitatory potential would be unmasked, leading not only to enhanced excitation of BLA projection neurons but also to the eventual activation of NMDA receptor-mediated long-term changes in synaptic plasticity (Clugnet and LeDoux, 1990). Our data suggest that during an acute stress response, local release of CRF into the BLA may act to transiently dampen inhibitory transmission and potentiate excitatory transmission, thereby facilitating memory formation. In keeping with this hypothesis, memory formation and consolidation of aversive events are dependent on NMDA receptor activation in the BLA (McGaugh and Roozendaal, 2002; Walker and Davis, 2002). Memory consolidation is blocked by infusion of CRF receptor antagonists into the BLA immediately after training but not 3 hr after training (Roozendaal et al., 2002). Similarly, we observed no significant alterations in network excitability after an acute infusion of an anxiogenic-like dose of Ucn into the BLA, which would also support the transient nature of the CRF response.

In contrast, after Ucn priming of the BLA, a reduction of $\mathrm{GABA}_{\mathrm{A}}$ receptor-mediated inhibition appears to have become hard-wired into the properties of the network, such that enhanced excitability is now observed up to 5 weeks after the last CRF infusion. At present, the mechanisms underlying this longlasting alteration in fast GABA transmission remain unknown. However, activation of presynaptic kainate receptors located on GABAergic terminals results in a depression of GABAergic transmission in the hippocampus, and this depression is facilitated at times when glutamatergic transmission is enhanced (Ali et al., 2001; Behr et al., 2002). The BLA has a particularly high density of low-affinity kainate receptors (Bailey et al., 2001). Consequently, CRF release in the BLA may modulate the activity of kainate receptors located on GABAergic terminals and further depress GABA release. Moreover, the response of BLA projection neu- rons to exogenously applied muscimol was unaffected by the priming paradigm, which would also suggest a possible presynaptic locus for the effects of repeated CRF administration. However, this technique cannot exclude the possibility that siteinput-specific decrements in $\mathrm{GABA}_{\mathrm{A}}$ receptor function may occur in the dendrites of BLA projection neurons with $U \mathrm{cn}$ priming. Indeed, recent data suggest that the number and stability of membrane-bound $\mathrm{GABA}_{\mathrm{A}}$ receptors and their ability to form functional clusters is regulated by protein kinase $\mathrm{A}$ and $\mathrm{PKC}$ and several subcellular proteins (Brandon et al., 2000; Bedford et al., 2001). Hence, repeated activation of second messenger cascades by $\mathrm{CRF}_{1}$ receptor activation may impact the ability of BLA neurons to form functional subsynaptic $\mathrm{GABA}_{\mathrm{A}}$ receptor clusters. Indeed, a dysfunction in $\mathrm{GABA}_{\mathrm{A}}$ receptor clustering has been proposed as a predisposing factor in panic disorder (Crestani et al., 1999).

Many intracellular cascades are initiated after NMDA receptor activation that lead to the development of synaptic plasticity. One particular signaling cascade is that of CaMKII. This kinase is unique in that after sufficient stimulation, autophosphorylation occurs and transforms it from a $\mathrm{Ca}^{2+}$-dependent to a $\mathrm{Ca}^{2+}$ independent state. In this hyperphosphorylated state, CaMKII activity will continue independently of the NMDA receptor activation (Lisman et al., 2002). Our findings are consistent with other behavioral studies that also show that antagonism of CaMKII within the BLA will block the acquisition of aversive behaviors (Tan and Liang, 1997) but not the expression of the behavior (Malinow et al., 1989). Paradoxically, acute CaMKII activation has been reported to enhance $\mathrm{GABA}_{\mathrm{A}}$ receptormediated transmission (Churn et al., 2002; Kawaguchi and Hirano, 2002). However, a preferential downregulation of $\mathrm{GABA}_{\mathrm{A}}$ receptors has been reported in the neocortex after withdrawal from periods of elevated $\mathrm{GABA}_{\mathrm{A}}$ receptor activation, resulting in hyperexcitability and seizure activity (S. S. Smith et al. 1998; Casasola et al., 2001). Five day Ucn priming induces a similar state of hyperexcitability. Sustained CaMKII activity could result in a transient elevation of $\mathrm{GABA}_{\mathrm{A}}$ receptor function and may trigger a subsequent downregulation of $\mathrm{GABA}_{\mathrm{A}}$ receptor expression.

Although the mechanisms involved in BLA Ucn priming are complex, the net result is a profound and long-lasting deficit in fast $\mathrm{GABA}_{\mathrm{A}}$ receptor-mediated inhibitory transmission. This deficit, in turn, contributes to an enhanced level of excitation within the BLA, and we propose that it is exactly this CRF receptormediated imbalance of excitatory and inhibitory processes within the BLA that triggers the development of psychopathology. Moreover, we report the unique development of lactate sensitivity in response to $U \mathrm{cn}$ priming. Significantly, lactate sensitivity is also a clinical feature of subjects with panic disorder and posttraumatic stress disorder (Maddock, 2001). To compound this issue, there is increasing evidence that anxiety and depression may increase the risk of adverse outcomes in several medical conditions, such as myocardial infarction. Therefore, we propose that CRF priming in the BLA represents a critical mechanism by which aberrant synaptic plasticity can translate the adverse effects of stress into human psychopathology and related medical disorders.

It should be noted that there is also compelling evidence from both animal and human subjects suggesting that the basolateral amygdala may participate in associative and attentional processes in both appetitive and aversive states, as well as in memory consolidation and drug addiction (Everitt et al., 1999; Gallagher and Schoenbaum, 1999; Davis and Whalen, 2001; Robbins and Ever- 
itt, 2002; Maren, 2003; McIntyre et al., 2003). Consequently, the results from our current study may have broader implications beyond the development of anxiety and could provide a putative mechanism for the development of a variety of maladaptive affective responses. Additional elucidation of the priming mechanisms may be critical in our ability to not only devise prevention strategies for stress-induced disorders but also to elucidate the function of the basolateral amygdala in the development of affective states.

\section{References}

Adolphs R, Tranel D, Damasio AR (1998) The human amygdala in social judgment. Nature 393:470-474.

Ali AB, Rossier J, Staiger JF, Audinat E (2001) Kainate receptors regulate unitary IPSCs elicited in pyramidal cells by fast-spiking interneurons in the neocortex. J Neurosci 21:2992-2999.

Arborelius L, Owens MJ, Plotsky PM, Nemeroff CB (1999) The role of corticotropin-releasing factor in depression and anxiety disorders. J Endocrinol 160:1-12.

Bailey A, Kelland EE, Thomas A, Biggs J, Crawford D, Kitchen I, Toms NJ (2001) Regional mapping of low-affinity kainite receptors in mouse brain using $\left[{ }^{3} \mathrm{H}\right](2 \mathrm{~S}, 4 \mathrm{R})$-4-methylglutamate autoradiography. Eur J Pharmacol 431:305-310.

Bale TL, Contarino A, Smith GW, Chan R, Gold LH, Sawchenko PE, Koob GF, Vale WW, Lee KF (2000) Mice deficient for corticotropin-releasing hormone receptors display anxiety-like behaviour and are hypersensitive to stress. Nat Genet 24:410-414.

Bedford FK, Kittler JT, Muller E, Thomas P, Uren JM, Merlo D, Wisden W, Triller A, Smart TG, Moss SJ (2001) GABA(A) receptor cell surface number and subunit stability are regulated by the ubiquitin-like protein Plic-1. Nat Neurosci 4:908-916.

Behr J, Gebhardt C, Heinemann U, Mody I (2002) Kindling enhances kainite receptor-mediated depression of GABAergic inhibition in rat granule cells. Eur J Neurosci 16:861-867.

Brandon NJ, Delmas P, Kittler JT, McDonald BJ, Sieghart W, Brown DA, Smart TG, Moss SJ (2000) GABAA receptor phosphorylation and functional modulation in cortical neurons by a protein kinase C-dependent pathway. J Biol Chem 275:38856-38862.

Britton KT, Lee G, Vale W, Rivier J, Koob GF (1986) Corticotropin releasing factor (CRF) receptor antagonist blocks activating and "anxiogenic" actions of CRF in the rat. Brain Res 369:303-306.

Callahan PM, Paris JM, Cunningham KA, Shinnick-Gallagher P (1991) Decrease of GABA-immunoreactive neurons in the amygdala after electrical kindling in the rat. Brain Res 555:335-339.

Casasola C, Bargas J, Arias-Montano JA, Calixto E, Montiel T, Galarraga E, Brailowsky S (2001) Hippocampal hyperexcitability induced by GABA withdrawal is due to down-regulation of GABA(A) receptors. Epilepsy Res 47:257-271.

Churn SB, Rana A, Lee K, Parsons JT, De Blas A, Delorenzo RJ (2002) Calcium/calmodulin-dependent kinase II phosphorylation of the GABAA receptor alphal subunit modulates benzodiazepine binding. J Neurochem 82:1065-1076.

Clugnet MC, LeDoux JE (1990) Synaptic plasticity in fear conditioning circuits: induction of LTP in the lateral nucleus of the amygdala by stimulation of the medial geniculate body. J Neurosci 10:2818-2824.

Cratty MS, Ward HE, Johnson EA, Azzaro AJ, Birkle DL (1995) Prenatal stress increases corticotropin-releasing factor (CRF) content and release in rat amygdala minces. Brain Res 675:297-302.

Crestani F, Lorez M, Baer K, Essrich C, Benke D, Laurent JP, Belzung C, Fritschey JM, Lüscher B, Mohler H (1999) Decreased GABAA-receptor clustering results in enhanced anxiety and a bias for threat cues. Nat Neurosci 2:833-839.

Critchley HD, Mathias CJ, Dolan RJ (2002) Fear conditioning in humans: the influence of awareness and autonomic arousal on functional neuroanatomy. Neuron 33:653-663.

Davis M, Whalen PJ (2001) The amygdala: vigilance and emotion. Mol Psychiatry 6:13-34

Dube T, Brunson T, Nehlig A, Baram TZ (2000) Activation of specific neuronal circuits by corticotropin releasing hormone as indicated by $\mathrm{c}-\mathrm{fos}$ expression and glucose metabolism. J Cereb Blood Flow Metab 20:1414-1424.
Dunn AJ, File SE (1987) Corticotropin-releasing factor has an anxiogenic action in the social interaction test. Horm Behav 21:193-202.

Everitt BJ, Parkinson JA, Olmstead MC, Arroyo M, Robledo P, Robbins TW (1999) Associative processes in addiction and reward. The role of amygdala-ventral striatal subsystems. Ann NY Acad Sci 877:412-438.

File SE (1990) One-trial tolerance to the anxiolytic effects of chlordiazepoxide in the plus-maze. Psychopharmacology (Berl)100:281-282.

Furmark T, Fischer H, Wik G, Larsson M, Fredrikson M (1997) The amygdala and individual differences in human fear conditioning. NeuroReport 8:3957-3960.

Gallagher M, Schoenbaum G (1999) Functions of the amygdala and related forebrain areas in attention and cognition. Ann NY Acad Sci 877:397-411.

Gean PW, Chang FC (1992) Ketamine suppresses synchronized discharges in the disinhibited amygdala slice. Brain Res Bull 26:923-927.

Gray TS, Bingaman EW (1996) The amygdala: corticotropin-releasing factor, steroids, and stress. Crit Rev Neurobiol 10:155-168.

Heinrichs SC, Pich EM, Miczek KA, Britton KT, Koob GF (1992) Corticotropin-releasing factor antagonist reduces emotionality in socially defeated rats via direct neurotropic action. Brain Res 581:190-197.

Heinrichs SC, Lapsansky J, Lovenberg TW, De Souza EB, Chalmers DT (1997) Corticotropin-releasing factor CRF1, but not CRF2, receptors mediate anxiogenic-like behavior. Regul Pept 71:15-21.

Kawaguchi SY, Hirano T (2002) Signaling cascade regulating long-term potentiation of $\mathrm{GABA}(\mathrm{A})$ receptor responsiveness in cerebellar Purkinje neurons. J Neurosci 22:3969-3976.

LeDoux JE (2000) The amygdala: second edition a functional analysis (Aggleton JP, ed), pp 289-310. Oxford: Oxford UP.

Lee Y, Schulkin J, Davis M (1994) Effect of corticosterone on the enhancement of the acoustic startle reflex by corticotropin releasing factor (CRF). Brain Res 666:93-98.

Li XF, Phillips R, LeDoux JE (1995) NMDA and non-NMDA receptors contribute to synaptic transmission between the medial geniculate body and the lateral nucleus of the amygdala. Exp Brain Res 105:87-100.

Lisman J, Schulman H, Cline H (2002) The molecular basis of CaMKII function in synaptic and behavioral memory. Nat Rev Neurosci 3:175-190

Maddock RJ (2001) The lactic acid response to alkalosis in panic disorder: an integrative review. J Neuropsychiatry Clin Neurosci 13:22-34.

Mahanty NK, Sah P (1999) Excitatory synaptic inputs to pyramidal neurons of the lateral amygdala. Eur J Neurosci 11:1217-1222.

Malinow R, Schulman H, Tsien RW (1989) Inhibition of post-synaptic PKC or CaMKII blocks induction but not expression of LTP. Science 245:862-866.

Maren S (2003) What the amygdala does and doesn't do in aversive learning. Learn Mem 10:306-308.

McGaugh JL, Roozendaal B (2002) Role of adrenal, stress hormones in forming lasting memories in the brain. Curr Opin Neurobiol 12:205-210.

McIntyre CK, Power AE, Roozendaal B, McGaugh JL (2003) Role of the basolateral amygdala in memory consolidation. Ann NY Acad Sci 985:273-293.

Merlo Pich E, Lorang M, Yeganeh M, Rodriguez de Fonseca F, Raber J, Koob GF, Weiss F (1995) Increase of extracellular corticotropin-releasing factor-like immunoreactivity levels in the amygdala of awaked rats during restraint stress and ethanol withdrawal as measured by microdialysis. J Neurosci 15:5439-5447.

Palkovits M, Brownstein MJ, Vale W (1983) Corticotropin releasing factor (CRF) immunoreactivity in hypothalamic and extrahypothalamic nuclei of sheep brain. Neuroendocrinology 37:302-305.

Rainnie DG (1999) Serotonergic modulation of neurotransmission in the rat basolateral amygdala. J Neurophysiol 82:69-85.

Rainnie DG, Asprodini EK, Shinnick-Gallagher P (1991a) Excitatory transmission in the basolateral amygdala. J Neurophysiol 66:986-998.

Rainnie DG, Asprodini EK, Shinnick-Gallagher P (1991b) Inhibitory transmission in the basolateral amygdala. J Neurophysiol 66:999-1009.

Rainnie DG, Fernhout BJ, Shinnick-Gallagher P (1992a) Differential actions of corticotropin releasing factor on basolateral and central amygdaloid neurons, in vitro. J Pharmacol Exp Ther 263:846-858.

Rainnie DG, Asprodini EK, Shinnick-Gallagher P (1992b) Kindlinginduced long-lasting changes in synaptic transmission in the basolateral amygdala. J Neurophysiol 67:443-454.

Rainnie DG, Asprodini EK, Shinnick-Gallagher P (1993) Intracellular re- 
cordings from morphologically identified neurons of the basolateral amygdala. J Neurophysiol 69:1350-1362.

Reul JM, Holsboer F (2002) Corticotropin-releasing factor receptors 1 and 2 in anxiety and depression. Curr Opin Pharmacol 2:23-33.

Robbins TW, Everitt BJ (2002) Limbic-striatal memory systems and drug addiction. Neurobiol Learn Mem 78:625-636.

Roozendaal B, Brunson KL, Holloway BL, McGaugh JL, Baram TZ (2002) Involvement of stress-released corticotropin-releasing hormone in the basolateral amygdala in regulating memory consolidation. Proc Natl Acad Sci USA 99:13908-13913.

Sajdyk TJ, Gehlert DR (2000) Astressin, a corticotropin releasing factor antagonist, reverses the anxiogenic effects of urocortin when administered into the basolateral amygdala. Brain Res 877:226-234.

Sajdyk TJ, Shekhar A (1997) Excitatory amino acid receptors in the basolateral amygdala regulate anxiety responses in the social interaction test. Brain Res 764:262-264.

Sajdyk TJ, Schober DA, Gehlert DR, Shekhar A (1999) Role of corticoptropin-releasing factor and urocortin within the basolateral amygdala of rats in anxiety and panic responses. Behav Brain Res 100:207-215.

Sanders SK, Morzorati SL, Shekhar A (1995) Priming of experimental anxiety by repeated subthreshold GABA blockade in the rat amygdala. Brain Res 699:250-259.

Shekhar A (1993) GABA receptors in the region of the dorsomedial hypothalamus of rats regulate anxiety in the elevated plus-maze test. I. Behavioral measures. Brain Res 627:9-16.

Smagin GN, Heinrichs SC, Dunn AJ (2001) The role of CRH in behavioral responses to stress. Peptides 22:713-724.

Smith BN, Dudek FE (1996) Amino acid-mediated regulation of spontaneous synaptic activity patterns in the rat basolateral amygdala. J Neurophysiol 76:1958-1967.

Smith GW, Aubry JM, Dellu F, Contarino A, Bilezikjian LM, Gold LH, Chen R, Marchuk Y, Hauser C, Bentley CA, Sawchenko PE, Koob GF, Vale W, Lee KF (1998) Corticotropin releasing factor 1-deficient mice display decreased anxiety, impaired stress response, and aberrant neuroendocrine development. Neuron 20:1093-1102.

Smith SS, Gong QH, Hsu FC, Markowitz RS, ffrench-Mullen JM, Li X (1998)
GABA(A) receptor alpha4 subunit suppression prevents withdrawal properties of an endogenous steroid. Nature 392:926-930.

Stenzel-Poore MP, Duncan JE, Rittenberg MB, Bakke A, Heinrichs SC (1996) CRH overproduction in transgenic mice: behavioral and immune system modulation. Ann NY Acad Sci 780:36-48.

Sutton RE, Koob GF, Le Moal M, Rivier J, Vale W (1982) Corticotropin releasing factor produces behavioural activation in rats. Nature 297:331-333.

Swerdlow NR, Geyer MA, Vale WW, Koob GF (1986) Corticotropinreleasing factor potentiates acoustic startle in rats: blockade by chlordiazepoxide. Psychopharmacology (Berl) 88:147-152.

Tan S-E, Liang K-C (1997) Inhibitory avoidance learning alters the amygdala calcium/calmodulin-dependent protein kinase KK activity in rats. Brain Res 748:227-233.

Tillfors M, Furmark T, Marteinsdottir I, Fischer H, Pissiota A, Langstrom B, Fredrikson M (2001) Cerebral blood flow in subjects with social phobia during stressful speaking tasks: a positron emission tomography study. Am J Psychiatry 158:1220-1226.

Timpl P, Spanagel R, Sillaber I, Kresse A, Reul JM, Stalla GK, Blanquet V, Steckler T, Holsboer F, Wurst W (1998) Impaired stress response and reduced anxiety in mice lacking functional corticotropin-releasing hormone receptor 1. Nat Genet 19:162-166.

Vale W, Spiess J, Rivier C, Rivier J (1981) Characterization of a 41-residue ovine hypothalamic peptide that stimulates secretion of corticotropin and beta-endorphin. Science 213:1394-1397.

Van Pett K, ViauV, Bittencourt JC, Chan RK, Li HY, Arias C, Prins GS, Perrin M, Vale W, Sawchenko PE (2000) Distribution of mRNAs encoding CRF receptors in brain and pituitary of rat and mouse. J Comp Neurol 428:191-212.

Vaughan J, Donaldson C, Bittencourt J, Perrin MH, Lewis K, Sutton S, Chan R, Turnbull AV, Lovejoy D, Rivier C, Sawchenko PE, Vale W (1995) Urocortin, a mammalian neuropeptide related to fish urotensin I and to corticotropin-releasing factor. Nature 378:287-292.

Walker DL, Davis M (2002) The role of amygdala glutamate receptors in fear learning, fear-potentiated startle, and extinction. Pharmacol Biochem Behav 71:379-392.

Yehuda R (2001) Biology of posttraumatic stress disorder. J Clin Psychiatry 62[Suppl 17]:41-46. 